\title{
ADSORPTIVE REMOVAL OF Fe (II) BY NaOH TREATED RICE HUSK: ADSORPTION EQUILIBRIUM AND KINETICS
}

\author{
Sunita Shrestha*, Anita Kumari Dhami* and Armila Rajbhandari (Nyachhyon)* \\ *Central Department of Chemistry, Tribhuvan University, Kirtipur, Nepal.
}

\begin{abstract}
The low cost adsorbents were prepared from raw rice husk (RRH) and $\mathrm{NaOH}$ treated rice husk (NRH). Then prepared materials were characterized by XRD, FTIR and surface area of rice husk adsorbent were determined by methylene blue adsorption method. XRD showed amorphous nature with low crystallinity of the material. The FTIR spectra showed the presence of oxygenated functional groups such as ester, phenol, carbonyl and silica on the material. The surface area of RRH and NRH were found to be 387 and $417 \mathrm{~m}^{2} / \mathrm{g}$ respectively. Thus, prepared adsorbents were used for the removal of $\mathrm{Fe}$ (II) ion from aqueous solution. The influence of various parameters like $\mathrm{pH}$, adsorbent doge, and contact time were studied for the better adsorption of Fe(II) on rice husk adsorbents. Results revealed that the maximum efficiency was achieved at $\mathrm{pH} 3$ for $\mathrm{Fe}$ (II). The adsorption process was found to be best fitted to Langmuir adsorption isotherm model controlled by pseudo-second-order kinetics with the rate constant value i.e. 0.0218 and $0.0235 \mathrm{~g} /(\mathrm{mg} \cdot \mathrm{min})$ for RRH and $\mathrm{NRH}$ respectively. The $\chi^{2}$ values of pseudo second order was found to be lower which confirmed chemisorption, involving ion exchange and valence forces through sharing or exchange of electrons between adsorbent and adsorbate. The maximum adsorption capacity for $\mathrm{Fe}(\mathrm{II})$ on $\mathrm{RRH}$ and $\mathrm{NRH}$ was found to be $2.9 \mathrm{mg} / \mathrm{g}$ and $5.6 \mathrm{mg} / \mathrm{g}$ respectively. The positive $\Delta \mathrm{G}$ value represents the randomness of the system during adsorption process. The slope of the linear plot of $Q_{t} v t^{0.5}$ was linear but not passed through the origin, which indicates that, the intraparticle diffusion was not only rate controlling step. Temkin value showed the maximum binding energy $\left(\mathrm{K}_{\mathrm{T}}\right)$ for $\mathrm{NRH}$ was $16.4 \mathrm{~L} / \mathrm{g}$ and for RRH it was $12.2 \mathrm{~L} / \mathrm{g}$.
\end{abstract}

Key word: Rice husk; Iron; Langmuir adsorption.

\section{INTRODUCTION}

Metals of having relatively high densities $\left(>5 \mathrm{~g} / \mathrm{cm}^{3}\right)$ and high atomic weights simply means heavy metals ${ }^{1}$. Copper, aluminium, iron, zinc, platinum, arsenic, chromium, etc are some of the examples. Heavy metals are either essential nutrients like iron, cobalt and zinc or relatively harmless such as ruthenium, silver and indium while other are highly poisonous such as arsenic, cadmium, mercury and lead ${ }^{1}$. Among the wide variety of heavy metals, iron i s one of the most common heavy metals that is found in nature. The magnetite $\left[\mathrm{Fe}_{3} \mathrm{O}_{4}, 72.4 \% \mathrm{Fe}\right]$, hematite $\left[\mathrm{Fe}_{2} \mathrm{O}_{3}, 69.9 \% \mathrm{Fe}\right]$, goethite $\quad[\mathrm{FeO}(\mathrm{OH}), \quad 62.9 \% \quad \mathrm{Fe}], \quad$ limonite $\left[\mathrm{FeO}(\mathrm{OH}) \cdot \mathrm{n}\left(\mathrm{H}_{2} \mathrm{O}\right)\right]$ or siderite $\left[\mathrm{FeCO}_{3}, 48.2 \% \mathrm{Fe}\right]$ are the most common ore of iron that is found in earth's crust.
Among them, hematite and magnetite are found in the form of rocks ${ }^{2}$ which during demineralization introduced in ground water by leaching and percolation. It also introduced from anthropogenic sources specially from industrial sector $^{3}$.

Heavy metals have become one of the major causes of concern for water pollution ${ }^{1}$. In ground water, iron exists in ferrous state and remains dissolved in water. Nonetheless when it is exposed to atmosphere, it gets oxidised to ferric ion. The iron in ferric state does not dissolved in water and forming reddish brown colour ${ }^{2}$. The relatively high content of iron levels in water can cause stains in plumbing, laundry and cooking utensils that can impart objectionable tastes and colours to foods ${ }^{3}$. Additionally, excessive

Author for Correspondence: Armila Rajbhandari (Nyachhyon), Central Department of Chemistry, Tribhuvan University, Kirtipur, Nepal. E-mail: armila3@yahoo.com

Received: 30 May 2020; First Review: 22 Sep 2020; Second Review: 23 Sep 2020; Accepted: 27 Sep 2020. Doi: https://doi.org/10.3126/sw.v14i14.34991 
concentration of iron intake causes life threatening issues such as diabetes, heart failure, under developed growth ${ }^{3}$, haemachromatosis ${ }^{2}$, anorexia, oliguria etc ${ }^{4,5}$. According to WHO, $0.3 \mathrm{mg} / \mathrm{L}$ of iron in drinking water is the water permissible level ${ }^{2}$. When it is higher than permissible level, one has to remove iron from drinking water for health purposes. In these days, different methods has been adopted such as chemical precipitation, lime coagulation, ion exchange, reverse osmosis, solvent extraction, reduction, electrodialysis, evaporation, electrochemical precipitation ${ }^{4}$, oxidation with oxidising agent such as chlorine and potassium permanganate and treatment with lime stone ${ }^{5}$.

However, these methods are not widely acceptable due to high capital, operational costs and problem in disposal of residual metal sludge. Taking these into considerations, the adsorption process thus appeared as one of the most promising methods ${ }^{6}$. It is considered as an efficient, convenient and economic method for waste water treatment.

In present study, rice husk was used as an adsorbent. Rice husk is actually the outer most covering of the rice grain. It contains $15-20 \%$ hemicellulose, $28-30 \%$ cellulose, $25-30 \%$ lignin, $15-20 \%$ silica and 10-15\% moisture ${ }^{7}$. This composition of rice husk makes it possible to be regarded as an adsorbent and the large amount of silica in the rice husk means that it could provide sufficient structural strength without cross linking ${ }^{8}$. Previous researchers has used rice husk for the removal of ionic dyes, basic dyes and variety of metal cations ${ }^{9-11}$.

In this context, the activated carbon (AC) was commonly used as an adsorbent. However, due to its high cost and its high affinity towards high molecular weight organic molecules, it is unable to adsorb heavy metal ions. To overcome this problem, many researchers have shown interest to search and explore on other potential adsorbents to replace $\mathrm{AC}^{6}$ synthesized and chemically modified adsorbent have been used.

In the present research work, the rice husk waste collected from rice mills of Kathmandu valley and used for the adsorptive removal of Fe (II) from aqueous solution.

\section{MATERIALS AND METHODS}

\section{Instruments}

The X-Ray Diffractometer (D2-Phaser, Bruker, Germany) was used to study the phase state of rice husk. It was operated at an accelerating voltage of $40 \mathrm{KV}$ and current 40 $\mathrm{mA}$ with $\mathrm{Cu}-\mathrm{K} \alpha$ radiation $\left(\lambda=1.5418 \mathrm{~A}^{\circ}\right)$ in the diffraction angle of 10 to 50 degrees. Likewise, the surface functional group was studied by Fourier Transmission Infrared Spectroscopy (Shimadzu, Model No. IRTracer-100, Japan) and FTIR spectra were recorded at $4000-400 \mathrm{~cm}^{-1}$ wave number. The spectrophotometric analysis was carried out by using 2306 visible Spectrophotometer, (AB1211010, Electronics India) and with the help of deluxe $\mathrm{pH}$ meter (Max Electronics, India) pH of solution was measured.

\section{Reagents}

Analar grade (AR) reagents such as Ferrous ammonium sulphate, hydroxylamine hydrochloride, ammonium acetate, 1,10 Phenanthroline monohydrate, $\mathrm{NaOH}$, and methylene blue were procured from Merck Company India.

\section{Preparation of Adsorbents}

Fresh rice husk was collected from a local rice mill of Kathmandu. It was washed with distilled water and dried in sunlight and finally dried in oven at $60^{\circ} \mathrm{C}$. The rice husk was grounded into fine powder and sieved through $75 \mu \mathrm{m}$ mesh size. Thus, obtained adsorbent was designated as Raw Rice Husk (RRH).

\section{Preparation of $\mathrm{NaOH}$ treated rice husk (NRH)}

Raw rice husk powder was treated with $(0.5 \mathrm{~N}) \mathrm{NaOH}$ solution at room temperature for 4 hour $^{9}$. Excess of $\mathrm{NaOH}$ was removed by washing with distilled water and the material was dried at $40^{\circ} \mathrm{C}$. Thus, obtained base treated rice husk was designated as NRH.

\section{Determination of surface area by Methylene blue (MB) adsorption method}

Surface area of adsorbent is generally done by methylene blue adsorption method using equation (1).

$\mathrm{S}_{\mathrm{MB}}=\left(\mathrm{Q}_{\mathrm{m}} \cdot \mathrm{a}_{\mathrm{MB}} \cdot \mathrm{N} \times 10^{-20}\right) / \mathrm{M}$

Where, $\mathrm{S}_{\mathrm{MB}}=$ surface area $\left(\mathrm{m}^{2} / \mathrm{g}\right), \mathrm{Q}_{\mathrm{m}}=$ Maximum loading $(\mathrm{mg} / \mathrm{g}), \mathrm{a}_{\mathrm{MB}}=$ Cross section area of one molecule of $\mathrm{MB}=$ 197.2 $\mathrm{A}^{02}, \mathrm{~N}=$ Avogadro's No. $=6.023 \times 10^{23}, \mathrm{M}=$ Molecular weight of $\mathrm{MB}=319.84 \mathrm{~g} / \mathrm{mol}$. 
The amount of methylene blue adsorbed from each adsorbent was calculated by using equation (3). Where, $\mathrm{C}_{0}(\mathrm{mg} / \mathrm{L})$ is the concentration of the methylene blue solution at initial time $(\mathrm{t}=0), \mathrm{C}_{\mathrm{e}}(\mathrm{mg} / \mathrm{L})$ is the concentration of the methylene blue solution at equilibrium time which can be calculated by equation (2), V(L) is the volume of the solution treated and $\mathrm{M}(\mathrm{g})$ is the mass of the adsorbent. To determine the $\mathrm{Q}_{\mathrm{m}}, \mathrm{Q}_{\mathrm{e}}$ was plotted as a function of $\mathrm{C}_{\mathrm{e}}$.

$$
\begin{aligned}
& \mathrm{C}_{\mathrm{e}}=\text { Absorbance/Slope. } \\
& \mathrm{Q}_{\mathrm{e}}=\left(\mathrm{C}_{\mathrm{o}}-\mathrm{C}_{\mathrm{e}}\right) \times \mathrm{V} / \mathrm{M} \ldots
\end{aligned}
$$

By using the Langmuir adsorption isotherm, maximum loading $\left(\mathrm{q}_{\mathrm{m}}\right)$ of $\mathrm{MB}$ on adsorbent sample was obtained. Then surface area was calculated by using equation (1)

\section{Batch adsorption study}

The batch adsorption study was used to access the adsorption capacity of adsorbent. The amount of metal ion adsorbed onto adsorbent was determined by using following equation (4).

$$
\mathrm{Q}_{\mathrm{t}}=\left(\mathrm{C}_{\mathrm{i}}-\mathrm{C}_{\mathrm{e}} / \mathrm{W}\right) \times \mathrm{V}
$$

Where, $C_{i}=$ Initial concentration of metal ion $(\mathrm{mg} / \mathrm{L}), \mathrm{W}=$ Weight of adsorbent (g). Likewise metal ion removal percentage was calculated by using the following equation.

$$
\mathrm{R} \%=(\mathrm{Ci}-\mathrm{Ce} / \mathrm{Ci}) \times 100
$$

$\mathrm{C}_{\mathrm{e}}=$ Equilibrium concentration of metal ion $(\mathrm{mg} / \mathrm{L}) . \mathrm{Qt}=$ Amount of metal ion adsorbed onto adsorbent at time ' $t$ ' $(\mathrm{mg} / \mathrm{g}), \mathrm{V}=$ Volume of metal ion solution (L).

\section{Adsorption Isotherm}

Langmuir, Freundlich and Temkin adsorption isotherm models were used to evaluate the adsorption efficiency. Likewise, error analysis for the isotherm and kinetics studies, analysis of intraparticle diffusion (Weber and Morris model) as well as influence on the removal of Fe(II) from aqueous solution by adsorbent was also studied.

\section{RESULTS AND DISCUSSION}

\section{X-Ray Diffraction Analysis}

The X-Ray diffraction spectrum of raw rice husk sample is presented in Fig. 1. In spectra, a peak at $23^{\circ}$ degree was observed which represents the low crystallinity of the material. It is assigned for silica present in raw rice husk. There are no other sharp peaks identified. The broad peaks could be seen which indicated for the typical amorphous form of the material ${ }^{12}$.

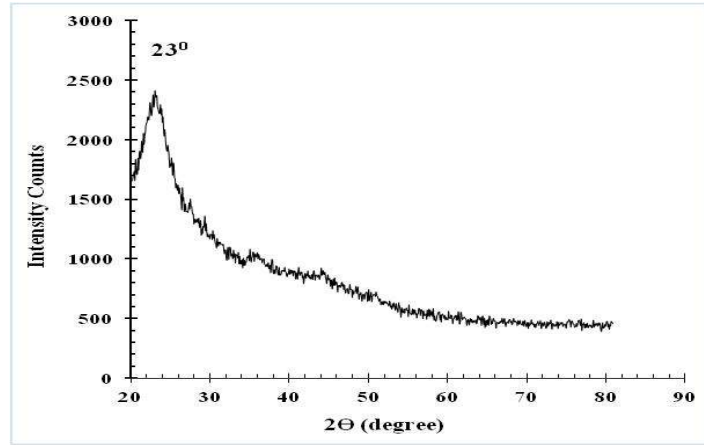

Figure 1: XRD spectrum of raw rice husk

\section{Fourier Transfer Infrared Spectroscopy Analysis}

FTIR spectra of raw rice husk, $\mathrm{NaOH}$ treated rice husk is shown in Error! Reference source not found., (a) represents the spectra of RRH whereas (b) spectra represents for NRH. In Fig. 2, the broad bands at around $3724,3296 \mathrm{~cm}^{-1}$ is assigned to $-\mathrm{OH}$ stretching vibration. Similarly, the next broad band at around $2872 \mathrm{~cm}^{-1}$ was observed which is assigned for the $\mathrm{C}-\mathrm{H}$ group. The band at 2349 and 2328 $\mathrm{cm}^{-1}$ has been assigned to symmetric or asymmetric stretching of aliphatic band of $-\mathrm{CH},-\mathrm{CH}_{2}$ or $-\mathrm{CH}_{3}$. Another small band at $2013 \mathrm{~cm}^{-1}$ may represent residual water. Similarly, the band observed at the region around 1749 , $1637,1508 \mathrm{~cm}^{-1}$ is assigned for the presence of $\mathrm{C}=\mathrm{O}$ stretching or $\mathrm{C}=\mathrm{C}$ stretching vibration of aromatic ring structure from lignin ${ }^{13}$. The small $\mathrm{C}-\mathrm{OH}$ bending bands were also observed at $1361 \mathrm{~cm}^{-1}$ which is attributed to ester. The major peak appeared at $1045 \mathrm{~cm}^{-1}$ ascribed for the bending vibration of $-\mathrm{CH}_{3}$ group or stretching $\mathrm{Si}-\mathrm{O}-\mathrm{Si}$ bond of siloxane ${ }^{14}$

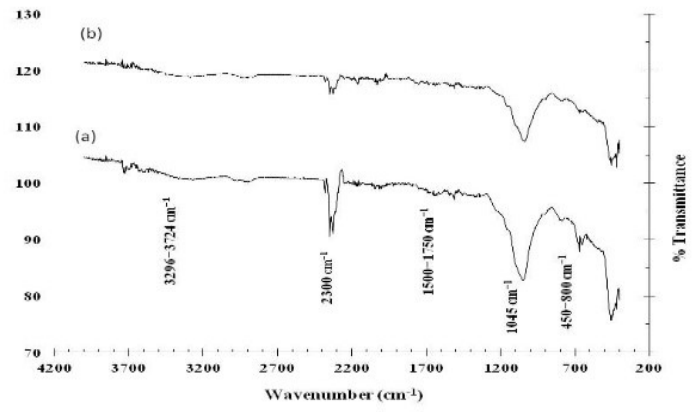

Figure 2: FTIR spectra of (a) RRH and (b) NRH 
Characteristic bands near 783, 669 and $451 \mathrm{~cm}^{-1}$ were assigned to the bending vibration of $\mathrm{Si}-\mathrm{O}$ bond from amorphous silica ${ }^{15,16}$. Another small band at 418 and 399 $\mathrm{cm}^{-1}$ are assigned for $\mathrm{C}-\mathrm{C}$ stretching bond.

Spectra (b) of NRH shows the similar bands at same wavenumber $\left(\mathrm{cm}^{-1}\right)$, however at 2300, 1045, 669 and 451 $\mathrm{cm}^{-1}$, the peak of intensity found to be reduced. This may be due to removal of lignin, cellulose by $\mathrm{NaOH}$ treatment on RRH. The increase of surface area of adsorbent, may be due to the formation of porosity on surface ${ }^{17,18}$.

Determination of specific surface area of adsorbents

Specific surface area of adsorbent was determined and are shown in table 1.

Table 1. Surface area of RRH and NRH

\begin{tabular}{cc}
\hline Adsorbents & Specific surface area $\left(\mathrm{m}^{2} / \mathbf{g}\right)$ \\
\hline RRH & 387 \\
\hline NRH & 417 \\
\hline
\end{tabular}

As can be seen in Table 1, the specific surface area of the $\mathrm{NRH}$ was found to be higher than RRH due to the more adsorption site formed with more numbers of pores in NRH than RRH. Surface area of rice husk is compared with other previous literature ${ }^{15,19,20}$ and was found to be in good agreements. It can be observed that the variation of surface area may be due to variation of temperature on the process of heating, stage of preparation, retention time for activation and pyrolysis.

Study on the removal of $\mathrm{Fe}(\mathrm{II})$ from solution by rice husk samples: Effect of initial pH of Fe(II) solution

The optimal $\mathrm{pH}$ for the removal of $\mathrm{Fe}(\mathrm{II})$ from aqueous solution by rice husk sample was found to be 3 . The optimum uptake of $\mathrm{Fe}^{++}$by RRH and NRH was found to be $91.5 \%$ and $95.5 \%$ respectively at $\mathrm{pH} 3$. Among these two adsorbents, $\mathrm{NaOH}$ treated adsorbent showed better result. It may be due to formation of porosity on surface by base treatment where removal of low molecular weight cellulose and lignin may occur ${ }^{17,18}$.

\section{Effect of Adsorbent Dose and Contact Time}

The $1.5 \mathrm{~g}$ of RRH adsorbent and $1.0 \mathrm{~g}$ of $\mathrm{NRH}$ adsorbents were found to be optimum adsorbent dose to carry out adsorption studies.

Similarly, the effect of contact time was studied. The equilibrium time for $99.4 \% \mathrm{Fe}(\mathrm{II})$ adsorption on NRH was found to be $60 \mathrm{~min}$ whereas equilibrium time for $98.35 \%$ adsorption of $\mathrm{Fe}(\mathrm{II})$ by RRH was found to be $180 \mathrm{~min}$.

Adsorption Kinetics Studies: Adsorption kinetics provides a deeper insight into how the amount of adsorbate changes with time and information about the equilibrium time. The pseudo first order kinetic model was studied for the reversible reaction when an equilibrium being established between liquid and solid phase. The linearized form of pseudo first order model is generally expressed as follows:

$\mathrm{dQ}_{\mathrm{t}} / \mathrm{dt}=\mathrm{K}_{1}\left(\mathrm{Q}_{\mathrm{e}}-\mathrm{Q}_{\mathrm{t}}\right)$

Where, $Q_{e}(\mathrm{mg} / \mathrm{g})$ is the amount of metal ion adsorbed at equilibrium, $\mathrm{Q}_{\mathrm{t}}(\mathrm{mg} / \mathrm{g})$ is the amount of metal ion adsorbed at any time' $t$ ' and $K_{1}$ is the Lagergren rate constant for pseudo first order adsorption reaction. After integration and applying boundary conditions, $\mathrm{t}=0$ to $\mathrm{t}=\mathrm{t}$ and $\mathrm{Q}_{\mathrm{t}}=0$ to $\mathrm{Q}_{\mathrm{t}}$ $=\mathrm{Q}_{\mathrm{t}}$, the linear form of equation (6) becomes;

$\log \left(\mathrm{Q}_{\mathrm{e}}-\mathrm{Q}_{\mathrm{t}}\right)=\log \mathrm{Q}_{\mathrm{e}}-\left(\mathrm{K}_{\mathrm{l}} \mathrm{t} / 2.303\right)$

The plot of $\log \left(\mathrm{Q}_{\mathrm{e}}-\mathrm{Q}_{\mathrm{t}}\right)$ vs t should give a straight line from which $\mathrm{K}_{1}$ and $\mathrm{Q}_{\mathrm{e}}$ can be determined from slope and intercept of the plot. The Kinetic parameters obtained are tabulated in Table 2 where low correlation coefficient $\left(\mathrm{R}^{2}\right)$ value for both the adsorbents i.e. 0.8294 for RRH and 0.8643 for $\mathrm{NRH}$ could be seen. The $\chi^{2}$ value was also noted which was found to be 1.26 for RRH and 28.94 for NRH.

By observing the parameter obtained from the pseudo first order, the process of removal of $\mathrm{Fe}(\mathrm{II})$ was not clear so further pseudo second order rate equation has been studied which may help to study the kinetics of adsorption of heavy metals onto adsorbent according to equation (8).

$\mathrm{dQ}_{\mathrm{t}} / \mathrm{dt}=\mathrm{K}_{2}\left(\mathrm{Q}_{\mathrm{e}}-\mathrm{Q}_{\mathrm{t}}\right)^{2}$

Where, $K_{2}(\mathrm{mg} / \mathrm{g} / \mathrm{min})$ is the pseudo second order rate constant and $\mathrm{Q}_{\mathrm{e}}$ and $\mathrm{Q}_{\mathrm{t}}$ are the amount of metal ion removed at equilibrium and at time ' $\mathrm{t}$ ', respectively, in $(\mathrm{mg} / \mathrm{g})$. On integration and applying boundary conditions, $\mathrm{t}=0$ to $\mathrm{t}=\mathrm{t}$ and $\mathrm{Q}_{\mathrm{t}}=0$ to $\mathrm{Q}_{\mathrm{t}}=\mathrm{Q}_{\mathrm{t}}$, the above equation (8) becomes, $\mathrm{t} / \mathrm{Q}_{\mathrm{t}}=1 / \mathrm{K}_{2} \mathrm{Q}^{2}+\left(1 / \mathrm{Q}_{\mathrm{e}}\right) \times \mathrm{t} \ldots \ldots$..(9)

$\mathrm{t} / \mathrm{Q}_{\mathrm{t}}=1 / \mathrm{v}_{0}+\left(1 / \mathrm{Q}_{\mathrm{e}}\right) \times \mathrm{t}$

Where, $v_{0}$ is the initial adsorption rate in $\mathrm{mg} / \mathrm{g} / \mathrm{min}$ and is equal to $\mathrm{K}_{2} \mathrm{Qe}^{2}$. 
Table 2. Kinetic parameter

\begin{tabular}{cccccccc}
\hline Adsorbents & \multicolumn{2}{c}{ Pseudo first order } & & \multicolumn{3}{c}{ Pseudo second order } \\
\cline { 2 - 4 } \cline { 6 - 8 } & $\begin{array}{c}\mathbf{K}_{\mathbf{1}} \\
\left(\mathbf{m i n}^{-\mathbf{1}}\right)\end{array}$ & $\mathbf{R}^{\mathbf{2}}$ & $\chi^{\mathbf{2}}$ & & $\begin{array}{c}\mathbf{K}_{\mathbf{2}} \\
\left(\mathbf{m g} \mathbf{g}^{-\mathbf{1}} \mathbf{m i n}^{-\mathbf{1}} \mathbf{)}\right.\end{array}$ & $\mathbf{R}^{\mathbf{2}}$ & $\chi^{\mathbf{2}}$ \\
\hline RRH & 0.0218 & 0.8294 & $\mathbf{1 . 2 6}$ & & 2.504 & 1 & $7.25 \times 10^{-5}$ \\
\hline NRH & 0.0235 & 0.8643 & 28.94 & & 3.081 & 0.9998 & $5.91 \times 10^{-5}$ \\
\hline
\end{tabular}

From the data of kinetic parameters, it can be seen that $\mathrm{K}^{2}$ and $\chi^{2}$ value was found to be higher which implies that the removal of $\mathrm{Fe}(\mathrm{II})$ by $\mathrm{RRH}$ sample follows pseudo second order kinetics model with better $\mathrm{R}^{2}$ value 1 and 0.9998 for NRH sample as compared with pseudo first order kinetic models.

\section{Error analysis for kinetics studies}

In order to conform the observations, error analysis was carried out using the chi square test $\left(\chi^{2}\right)$ for experimental data as well as the calculated data in given time interval and in different concentration. The mathematical expression is;

$\chi^{2}=\sum\left[\left(\mathrm{q}_{\mathrm{t}}-\mathrm{q}_{\mathrm{tm}}\right)^{2} / \mathrm{q}_{\mathrm{tm}}\right]$

Where, $\mathrm{q}_{\mathrm{t}}=$ adsorption capacity obtained by experimental value $(\mathrm{mg} / \mathrm{g})$ and $\mathrm{q}_{\mathrm{tm}}=$ adsorption capacities obtained by using the model $(\mathrm{mg} / \mathrm{g})$.

If the calculated data from model are similar to the experimental data, the value of $\chi^{2}$ will be smaller, while if these values differ, then the value of $\chi^{2}$ will be larger ${ }^{5}$. Here, the corresponding values of $\chi^{2}$ are tabulated in Table 2 which showed that $\chi^{2}$ values is lower for pseudo second order compared to pseudo first order.

Hence, the adsorption of $\mathrm{Fe}(\mathrm{II})$ onto rice husk sample follows pseudo second order kinetics. The pseudo second order confirmed the chemisorption, involving ion exchange and valence forces through sharing or exchange of electrons between adsorbent and adsorbate ${ }^{21}$.

\section{Analysis of intraparticle diffusion (Weber and Morris model)}

Intraparticle diffusion model was applied to determine the mechanism and the rate determining step in adsorption process. The rate constants of intraparticle diffusion $\left(\mathrm{K}_{\mathrm{id}}\right)$ are determined by using the following Weber-Morris equation $(12)^{22,23}$.

$\mathrm{Q}_{\mathrm{t}}=\mathrm{K}_{\mathrm{id}} \mathrm{t}^{0.5}+\mathrm{C}$

Where, $K_{\text {id }}\left(\mathrm{mg} / \mathrm{g} . \min ^{0.5}\right)$ represents the intraparticle diffusion rate constant and its values are obtained from the plot of $Q_{t}$ versus $t^{0.5}$ and value of ' $C$ ' is obtained from the intercept of the plot and represented the boundary layer effect. The larger the value of $\mathrm{C}$, the greater is the boundary layer effect.

Here (Fig. 3), the intraparticle diffusion curve was found to be linear and was not passed through the origin showing the intercept C. It was described that the adsorption was partly controlled by intraparticle diffusion ${ }^{14}$. Therefore, the adsorption here was also controlled by external adsorption.

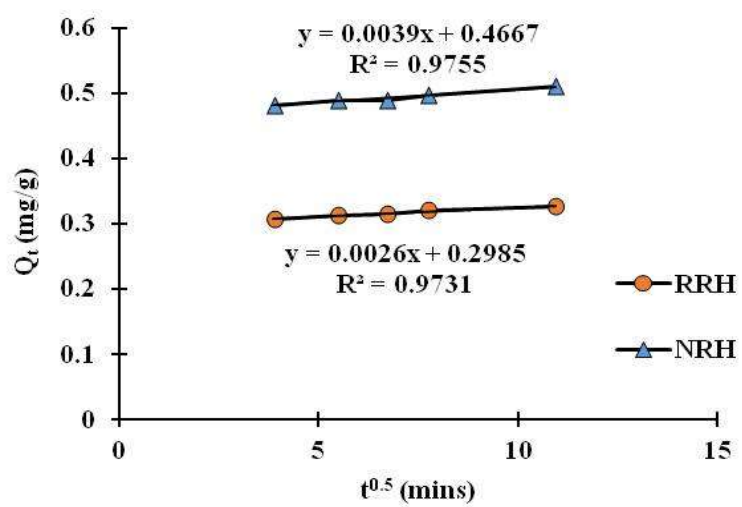

Figure 3: A plot of $Q_{t}$ versus $t^{0.5}$ 
Table 3. Langmuir parameters, Freundlich parameter and Temkin paramet

\begin{tabular}{|c|c|c|c|c|c|c|c|c|c|c|}
\hline \multirow[t]{2}{*}{ Adsobents } & \multicolumn{5}{|c|}{ Langmuir parameters } & \multicolumn{3}{|c|}{ Freundlich parameters } & \multicolumn{2}{|c|}{$\begin{array}{c}\text { Temkin } \\
\text { parameters }\end{array}$} \\
\hline & $\mathrm{b}$ & $\mathrm{Q}_{\mathrm{m}}$ & $\mathrm{R}^{2}$ & $\mathrm{~K}_{\mathrm{L}}$ & $\mathrm{G}^{0}$ & $1 / \mathrm{n}$ & $\mathrm{K}_{\mathrm{F}}$ & $\mathrm{R}^{2}$ & $\mathrm{~B}$ & $\mathrm{~K}^{\mathrm{T}}$ \\
\hline $\mathrm{RRH}$ & 0.3 & 2.9 & 0.996 & $\begin{array}{l}0.017- \\
0.257\end{array}$ & 3.1 & 0.46 & 1.98 & 0.9677 & 0.24 & 12.4 \\
\hline $\mathrm{NRH}$ & 0.9 & 5.6 & 0.997 & $\begin{array}{l}0.006- \\
0.107\end{array}$ & 0.2 & 0.54 & 1.42 & 0.9741 & 0.98 & 16.4 \\
\hline
\end{tabular}

\section{Adsorptions Isotherm Studies}

To evaluate the feasibility, three different isotherm models have been tested.

\section{a. Langmuir isotherm model}

It is widely applied model to describe experimental adsorption data based on the assumption that maximum adsorption corresponding to saturated monolayer of adsorbate molecule on adsorbate surface with a constant energy and no further adsorption. The Langmuir adsorption equation can be represented as; $Q \mathrm{Qe}=$ $\frac{\mathrm{Q}_{\mathrm{m}} \mathrm{bC}}{1+\mathrm{bC}}$

The linear form of Langmuir expression is expressed as;

$\frac{\mathrm{C}_{\mathrm{e}}}{\mathrm{q}_{\mathrm{e}}}=\frac{1}{\mathrm{Q}_{\mathrm{m}} \mathrm{b}}+\frac{1}{\left(\mathrm{Q}_{\mathrm{e}}\right)} \mathrm{Ce}$

Where, $\mathrm{Q}_{\mathrm{e}}(\mathrm{mg} / \mathrm{g})$ is the amount of adsorbate adsorbed per unit mass of adsorbent; $\mathrm{Ce}(\mathrm{mg} / \mathrm{L})$ is the equilibrium concentration of the adsorbate in solution after adsorption; Qm $(\mathrm{mg} / \mathrm{g})$ is the maximum adsorption capacity corresponding to monolayer coverage of adsorbents and $b$ $(\mathrm{L} / \mathrm{mg})$ is the adsorption equilibrium constant.

Here, the value of $Q_{m}$ and $b$ are presented in Table 3 which was calculated from the slope and intercept of the $C_{e} / Q_{e}$ versus $\mathrm{C}_{\mathrm{e}}$ plot. The chemical modification of $\mathrm{RRH}$ resulted in enhancing the sorption capacity from $2.9 \mathrm{mg} / \mathrm{g}$ to 5.6 $\mathrm{mg} / \mathrm{g}$ which was compared with various literature ${ }^{5,10,22}$ and found to be good agreement with literature values of wooden charcoal ${ }^{5}$ and calabrian pine bark $^{22}$. Langmuir isotherm constant (b) was found to be 0.9 and $0.3 \mathrm{~L} / \mathrm{mg}$ for $\mathrm{NRH}$ and RRH respectively which indicates free energy of adsorption. Here, the value of $\mathrm{G}^{0}$ represents the randomness of the system during adsorption process where it was found to be 3.1 for RRH and 0.2 for NRH. The essential feature of Langmuir adsorption isotherm can be expressed in terms of dimensionless constant called separation factor or Langmuir parameter $\left(\mathrm{K}_{\mathrm{L}}\right)$ which was found to be $0.006-0.107$ for NRH and $0.017-0.257$ for RRH. These values of $K_{\mathrm{L}}$ lies between 0 and 1 indicating the favourability of adsorption. Here, $\mathrm{K}_{\mathrm{L}}$ was calculated by equation (15);

$$
\mathrm{K}_{\mathrm{L}}=1 /\left(1+\mathrm{bC}_{\mathrm{i}}\right) \text {. }
$$

Where, $\mathrm{C}_{\mathrm{i}}=$ Initial concentration $(\mathrm{mg} / \mathrm{L})$ and $\mathrm{b}=$ Langmuir constant

The correlation coefficient $\mathrm{R}^{2}$ value are closer to unity for $\mathrm{NRH}$ and RRH which indicated that linear isotherm is fitted for both NRH and RRH sample.

\section{b. Freundlich isotherm model}

The adsorption data was also tested through Freundlich Adsorption Isotherm model. The model explains the nonideal sorption that involves heterogeneous surface energy system and is expressed by equation (16).

$$
\mathrm{Q}_{\mathrm{e}}=\mathrm{K}_{\mathrm{F}} \mathrm{C}_{\mathrm{e}}^{\frac{1}{\mathrm{n}}}
$$

The linear form can be written as; $\log \mathrm{qe}=\log \mathrm{K}_{\mathrm{F}}+$ $\frac{1}{n} \log C_{e} \ldots \ldots \ldots(17)$ where, $K_{F}$ and $n$ (dimensionless constants) are the Freundlich adsorption isotherm constants, $\mathrm{K}_{\mathrm{F}}$ indicates adsorption capacity which was found to be $1.98 \mathrm{mg} / \mathrm{g}$ for RRH and $1.42 \mathrm{mg} / \mathrm{g}$ for $\mathrm{NRH}$. The slope $1 / \mathrm{n}$ ranging between 0 and 1 , is favourable adsorption condition and was found to be 0.54 and 0.46 for NRH and RRH respectively (Table 3 ) which indicates the favourable adsorption behaviour of $\mathrm{Fe}(\mathrm{II})$ from aqueous solution by RH sample however the correlation coefficient value obtained from Freundlich isotherm for RRH and NRH was found to be 0.9677 and 0.9741 which appeared to be lower than the Langmuir isotherm value i.e. 0.996 (RRH) and 0.997 (NRH). It clearly revealed that Langmuir model was best fitted one. 


\section{c. Temkin isotherm model}

After observing these two models, the effect of interaction of adsorbate and adsorbent was studied by Temkin adsorption isotherm model. This model assumes that heat of adsorption of all the molecules in the layer would decrease linearly rather than logarithmically with coverage due to adsorbate adsorbent interaction and adsorption is characterized by uniform distribution of binding energy up to some maximum binding energy. The linearized Temkin equation is given by the following equation.

$$
\begin{aligned}
& \mathrm{Q}_{\mathrm{e}}=(\mathrm{RT} / \mathrm{b}) \log \mathrm{K}_{\mathrm{T}} \mathrm{C}_{\mathrm{e}} . \\
& \mathrm{Q}_{\mathrm{e}}=\mathrm{BInK}_{\mathrm{T}}+\mathrm{BInC}_{\mathrm{e}} .
\end{aligned}
$$

Where, $(\mathrm{RT} / \mathrm{b})=\mathrm{B}, \mathrm{K}_{\mathrm{T}}=$ Temkin isotherm equilibrium binding constant $(\mathrm{L} / \mathrm{g})$, which corresponds to maximum binding energy, $\mathrm{b}=$ Temkin isotherm constant, $\mathrm{R}=$ Universal gas constant $(8.314 \mathrm{~J} / \mathrm{mol} / \mathrm{K}), \mathrm{T}=$ temperature at $298 \mathrm{~K}, \mathrm{~B}=$ constant related to heat of sorption $(\mathrm{J} / \mathrm{mol})$

The Temkin constants $\mathrm{K}_{\mathrm{T}}$ and $\mathrm{b}$ is calculated from the slope and intercept of $Q_{e}$ as a function of $\operatorname{lnC}_{e}{ }^{24}$ and the data are presented in Table 3, where heat of sorption (B) was found to be $0.24 \mathrm{~J} / \mathrm{mol}$ for $\mathrm{RRH}$ and $0.98 \mathrm{~J} / \mathrm{mol}$ for $\mathrm{NRH}$. The maximum binding energy $\left(\mathrm{K}_{\mathrm{T}}\right)$ was found to be $12.2 \mathrm{~L} / \mathrm{g}$ for $\mathrm{RRH}$ and $16.4 \mathrm{~L} / \mathrm{g}$ for $\mathrm{NRH}$ indicates greater interaction of adsorbate and adsorbent in NRH

\section{CONCLUSION}

It is concluded that simple and low cost bio adsorbents can be prepared from rice husk and chemical modification can be done by base $(\mathrm{NaOH})$ treatment. Both adsorbent samples were able to uptake maximum $\mathrm{Fe}(\mathrm{II})$ at $3.0 \mathrm{pH}$. Adsorption capacity of rice husk sample was enhancing from $2.9 \mathrm{mg} / \mathrm{g}$ to $5.6 \mathrm{mg} / \mathrm{g}$ after chemical treatment by $\mathrm{NaOH}$. The adsorption capacity of NRH was found to be 2 times greater than RRH. Then, experimental data were better fitted for Langmuir isotherm model which indicates the homogenous distribution of active sites on the surface of adsorbent and from the Temkin model it was concluded that maximum binding energy was greater for adsorption of $\mathrm{Fe}$ (II) onto NRH. Similarly, the kinetics for uptake of Fe(II) by RH sample has followed the pseudo second order kinetic model which indicated the chemisorption occurred as the rate limiting mechanism. And from intraparticle diffusion model, it is concluded that the adsorption was partly controlled by intraparticle diffusion and also controlled by external adsorption.

\section{ACKNOWLEDGEMENT}

Authors are thankful to Prof. Dr. Ram Chandra Basnyat, Head of Central Department of Chemistry, Tribhuvan University, for providing physical facilities and grateful to Assoc. Prof. Dr. Sabita Shrestha and Dr. Khagraj Sharma for FTIR analysis. Special thanks to Nepal Academy of Science and Technology (NAST) for recording XRD.

\section{REFERENCE}

1. Ali, H. and Khan, E. 2018. What Are Heavy Metals? Long-Standing Controversy over the Scientific Use of the Term 'Heavy Metals' - Proposal of a Comprehensive Definition. Toxicological Environmental and Chemistry. 100: 6-19.

2. Akiladevi, A. R., Manimozhi, R., Renganathan, T. and Priya, M. D. 2017. Removal of Iron from Synthetic Waste Water Using Sawdust and Rice Husk. International Journal of Scientific and Engineering Research. 8: 92-97.

3. Kaveeshwar, A. R., Sanders, M., Ponnusamy, S. K., Depan, D. and Subramaniam, R. 2018. Chitosan as a Biosorbent for Adsorption of Iron (II) from Fracking Wastewater. Polymers for Advanced Technology. 29: 961-969.

4. Regmi, S., Ghimire, K. N., Pokhrel, M. R and Khadka, D. B. 2015. Adsorptive Removal and Recovery of Aluminium (III), Iron (II), and Chromium (VI) onto a Low Cost Functionalized Phragmities Karka Waste. Journal Institute of Science and Technology. 20: 145-152.

5. Ahamad, K. U. and Jawed, M. 2010. Kinetics, Equilibrium and Breakthrough Studies for Fe(II) Removal by Wooden Charcoal: A LowCost Adsorbent. Desalination. 251: 137-145.

6. Keng, P. S., Lee, S. L., Ha, S. T., Hung, Y. T. and Ong, S. T. 2014. Removal of Hazardous Heavy Metals from Aqueous Environment by Low-Cost Adsorption Materials. Environmental Chemistry Letters. 12: $15-25$.

7. Foo, K.Y. and Hameed, B.H. 2011. Utilization of rice husks as a feedstock for preparation of activated carbon by microwave induce $\mathrm{KOH}$ and $\mathrm{K}_{2} \mathrm{CO}_{3}$ activation. Bioresources Technology. 102: 9814-9817.

8. Low, K. S. and Lee, C. K. 1997. Quaternized Rice Husk as Sorbent for Reactive Dyes. Bioresources Technology. 61: 121-125.

9. Kumar, U. and Bandyopadhyay, M. 2006. Sorption of Cadmium from Aqueous Solution Using Pretreated Rice Husk. Bioresources Technology. 97: 104-109.

10. Zhang, Y., Zheng, R., Zhao, J., Ma, F., Zhang, Y. and Meng, Q. 2014. Characterization of $\mathrm{H}_{3} \mathrm{PO}_{4}$-Treated Rice Husk Adsorbent and Adsorption of Copper(II) from Aqueous Solution. Biomed Research International. 2014: 496878

11. Suemitsu, R., Uenishi, R., Akashi, I. and Nakano, M. 1986. The Use of Dyestuff-treated Rice Hulls for Removal of Heavy Metals from Waste Water. Journal of Applied Polymer Science. 31: 75-83. 
12. Ang, T. N., Ngoh, G. C., Chua, A. S. M. and Lee, M. G. 2012. Elucidation of the Effect of Ionic Liquid Pretreatment on Rice Husk via Structural Analyses. Biotechnology for Biofuels. 5: 1-10.

13. Syafri, R., Ahmad, I. and Abdullah, I. 2011. Effect of Rice Husk Surface Modification by LENR the on Mechanical Properties of NR/HDPE Reinforced Rice Husk Composite. Sains Malaysiana. 40: 749-756.

14. Daifullah, A. A. M., Girgis, B. S. and Gad, H. M. H. 2003. Utilization of Agro-Residues (Rice Husk) in Small Waste Water Treatment Plans. Materials Letters. 57: 1723-1731.

15. Shrestha, L., Thapa, M., Shrestha, R., Maji, S., Pradhananga, R. and Ariga, K. 2019. Rice Husk-Derived High Surface Area Nanoporous Carbon Materials with Excellent Iodine and Methylene Blue Adsorption Properties. Carbon. 5: 10.

16. Elhafez, S. E. A., Hamad, H. A., Zaatout, A. A., and Malash, G. F. 2017. Management of Agricultural Waste for Removal of Heavy Metals from Aqueous Solution: Adsorption Behaviors, Adsorption Mechanisms, Environmental Protection, and Techno-Economic Analysis. Environmental Science and Pollution Research. 24: 1397-1415.

17. Chauhan, S. 2015. Rice Husk as a Potential Adsorbent for Removal of Metal Ions - A Review. Der Chemica Sinica. 44: 999-1010.

18. Ioannidou, O. and Zabaniotou, A. 2007. Agricultural Residues as Precursors for Activated Carbon Production-A Review. Renewable and Sustainable Energy Review. 11: 1966-2005.

19. Lata, S. and Samadder, S. 2014. Removal of Heavy Metals Using Rice Husk: A Review. International Journal of Environmental Research and Development. 4: 165-170.

20. Shalaby, N. H., Ewais, E. M. M., Elsaadany, R. M., and Ahmed, A. 2017. Rice Husk Templated Water Treatment Sludge as Low Cost Dye and Metal Adsorbent. Egyptian Journal of Petroleum. 26: 661-668.

21. Sawasdee, S., Jankerd, H. and Watcharabundit, P. 2017. Adsorption of Dyestuff in Household-Scale Dyeing onto Rice Husk. Energy Procedia. 138: $1159-1164$

22. Acemioglu, B. 2004. Removal of Fe(II) Ions from Aqueous Solution by Calabrian Pine Bark Wastes. Bioresource Technology. 93: 99-102.

23. Yakout, S. M. 2014. Removal of the Hazardous, Volatile, and Organic Compound Benzene from Aqueous Solution Using Phosphoric Acid Activated Carbon from Rice Husk. Chemistry Central Journal. 8: 1-7.

24. Dada, A.O and Olalekan, A. 2012. Langmuir, Freundlich, Temkin and Dubinin-Radushkevich Isotherms Studies of Equilibrium Sorption of $\mathrm{Zn}^{2+}$ Unto Phosphoric Acid Modified Rice Husk. IOSR Journal of Applied Chemistry. 3: 38-45. 